Mirjana Lončar-Vujnović Radoje Šoškić

\title{
VILIJAM FOKNER I „CELA ISTINA” O LJUDSKIM BIĆIMA U PRIPOVETKAMA „VOŠ”, ,RUŽA ZA EMILI” I ROMANU DOK LEZ̆AH NA SAMRTI
}

Rad komentariše Foknerove pripovetke „Voš”, „Ruža za Emili” i roman Dok ležah na samrti iz perspektive kazivanja cele istine o ljudskim bićima, odnosno totalitetu čovekove egzistencije. Pri analizi pomenutih dela rad se služi idejama Oldosa Hakslija izloženim u njegovom uticajnom eseju naslovljenom „Tragedija i cela istina”. Osim toga, rad se dotiče i Foknerove kritike samog jezika kao manjkavog, arbitrarnog i nedostatnog u odnosu na stvarnost budući da nikada ne uspeva zahvatiti celinu stvari. Foknerov lingvistički skepticizam biće analiziran na primeru njegovog romana toka svesti Dok ležah na samrti.

Ključne reči: Fokner, „Voš”, „Ruža za Emili”, Dok ležah na samrti, tragedija, komedija, jezik, egzistencija.

Nobelova nagrada koju je američki pisac Vilijam Fokner dobio 1950. godine oživela je interesovanje za njegovo stvaralaštvo, koje ga je učinilo jednim od najistaknutijih i najkontroverznijih od svih američkih pisaca. Počevši od svog ranog romana Sartoris, gde je pisac kreirao imaginarni okrug po imenu Joknapatafa, Fokner je tokom svoje

Rad je nastao kao rezultat istraživanja koja se sprovode na projektu „Prevod u sistemu komparativnih izučavanja nacionalne i strane književnosti i kulture" (evidencioni broj 178019), koje u celosti finansira Ministarstvo prosvete, nauke i tehnološkog razvoja Republike Srbije. 
stvaralačke karijere ispričao povest o usponu i padu starog Juga, a potom i o istoriji posleratnog Juga, sve do godine 1940. Malkolm Kauli je o tome već pisao u izdanju Viking Portable Library Foknerovog opusa 1946. godine, ali je trebalo neko vreme - i pomoć Nobelove nagrade - ne bi li većina čitalaca shvatila značaj i veličanstvenost piščevog postignuća (Cowley 195̌1: 10). Po značaju njegov je opus nešto poput Balzakove serije romana o životu u Parizu od 1815̆. do 1848, što je omogućilo Fokneru da stvori korpus dela koji na gotovo mitološki način pokazuje istoriju Juga počev od doba starosedelaca Indijanaca do gotovo polovine 20. veka.

Neki od kritičara ranih dela Foknera odbacili su njegovo stvaralaštvo kao čisto regionalno orijentisano i preterano senzacionalno, uz obilje scena nasilja. Međutim, po prijemu Nobelove nagrade za književnost, Fokner je u svom govoru saopštio da je njegov rad o onome o čemu upravo govori vrhunska literatura: o ljubavi, časti, ponosu, sažaljenju, saosećanju i žrtvi. U Foknerovom svetu pobrojane vrline uvek su neraskidivo skopčane sa niskošću, grotesknim i komičnim, da ih je ponekad teško razaznati. O zadatku pisca jezgrovito svedoči sledeće:

[...] Osećam da ova nagrada nije data lično meni kao čoveku, već mojem umetničkom delu - životnom delu stvaranom u agoniji i znoju ljudskoga duha, ne radi slave a ponajmanje radi novčanog dobitka, nego da bi se iz materijala ljudskoga duha stvorilo nešto što pre nije postojalo.

[...] Naša današnja tragedija sadržana je u sveopštem i sveobuhvatnom fizičkom strahu koji je tako dugo podnošen da nam je posato podnošljiv. Ne postoje više problemi duha. Postoji samo jedno pitanje: „Kada ću odleteti u vazduh?" Usled ove zaokupljenosti, današnji mladi pisac ili spisateljica zaboravili su probleme ljudskog srca koje se nalaze u sukobu samo sa sobom, a jedino to može proizvesti čestito stvaralačko delo, jer je to jedino dostojno da se o njemu piše, dostojno stvaralačke muke i znoja.

Današnji mladi pisac ponovo mora da nauči te probleme. Mora sam sebe učiti da je strah najkukavičkiji od svega na svetu. I, učeći to, mora strah odagnati zauvek, ne sme ostaviti nimalo prostora u svojoj umetničkoj radionici bilo čemu drugom osim drevnim istinitostima i istinama srca, onim praiskonskim istinama, bez kojih je bilo koje stvaralačko delo kratkotrajno i na propast osuđeno - a to su: ljubav i čast i samilost i saučešće i požrtvovanost. Dok to ne nauči, kletva će tištati njegove napore. Neće pisati o ljubavi, nego o 
Mirjana Lončar-Vujnović, Radoje Šoškić: Vilijam Fokner i „,ela istina”...

pohoti, o porazima u kojima niko ništa vredno ne gubi, o pobedama bez nade i, što je najgore, bez samislosti i bez saučešća. Njegove tuge neće tugovati nad sveopštim kosturima, neće ostaviti nikakvih ožiljaka. Njegovo pero neće voditi uzbuđenja srca već porivi žlezda.

Dok ponovo ne nauči te istinitosti, pisaće tako poput radoznalog posmatrača koji stoji u masi i motri kraj čoveka. A ja odbijam da prihvatim kraj čoveka. Lako je ustvrditi da je čovek besmrtan zato što će odoleti, što će u času kada zvekne poslednji brecaj usuda i utihne kao jeka od poslednje bezvredne litice što lebdi bez plime i oseke u potonjem rumenilu umiruće večeri, što će se čak i u tom usudnom času čuti još jedan zvuk, zvuk čovekovog slabašnog neiscrpnog glasa, koji se stalno čuje. Ja neću da prihvatim ovakav vidik. Ja verujem da će čovek ne samo odoleti, on će i istrajati.

Čovek je besmrtan ne zbog toga što on sam među stvorovima poseduje neiscrpljiv glas, nego zato što poseduje dušu, duh koji je sposoban na saučešće, na pregaranje i na izdržljivost. Pesnikova, piščeva dužnost jeste da piše o tim vrlinama. Njegova je povlastica da pomogne čoveku da izdrži uzdižući mu srčanost, podsećajući ga na hrabrost, na čast, na nadu, na ponos, na samilost, na saučešće i na požrtvovanost, jer su te vrline bile čast i ponos njegove prošlosti. Pesnikov glas ne sme da bude samo izveštaj o čoveku, on može biti jedan od podupirača, jedan od stubova koji će podržavati čoveka da ustraje i da - pobedi. ${ }^{1}$

1 Navedeno prema: Nobel Lectures, Literature 1901-196\%, ed. Horst Frenz, Elsevier Publishing Company, Amsterdam, 1969. U originalu: "[...] I feel that this award was not made to me as a man, but to my work - a life's work in the agony and sweat of the human spirit, not for glory and least of all for profit, but to create out of the materials of the human spirit something which did not exist before. So this award is only mine in trust. It will not be difficult to find a dedication for the money part of it commensurate with the purpose and significance of its origin. But I would like to do the same with the acclaim too, by using this moment as a pinnacle from which I might be listened to by the young men and women already dedicated to the same anguish and travail, among whom is already that one who will some day stand here where I am standing.

[...] Our tragedy today is a general and universal physical fear so long sustained by now that we can even bear it. There are no longer problems of the spirit. There is only the question: When will I be blown up? Because of this, the young man or woman writing today has forgotten the problems of the human heart in conflict with itself which alone can make good writing because only that is worth writing about, worth the agony and the sweat.

He must learn them again. He must teach himself that the basest of all things is to be afraid; and, teaching himself that, forget it forever, leaving no room in his 
Prema Fokneru, ne samo da mladi pisci današnjice treba da pišu o uobičajenim tragedijama koje čovek doživljava, već i o emocionalnim sposobnostima ljudskog duha. Mi ćemo posmatrati Foknerove pripovetke i roman Dok ležah na samrti (As I Lay Dying) u svetlu testiranja čoveka, testa koji predočava „viziju ljudske egzistencije kao ludosti, apsurda; čoveka koji je beznačajan i komičan, ali ipak sposoban za značajan, iako ograničen, donkihotovski odgovor na ludosti života” (Rossky 1962: 87). . Vošovo postupanje naposletku, ludilo Emili Grirson kao i njen nepokolebljivi i beskompromisni stav, i Darlov užasni smeh čine okosnicu pomenutih priča i romana.

workshop for anything but the old verities and truths of the heart, the old universal truths lacking which any story is ephemeral and doomed - love and honor and pity and pride and compassion and sacrifice. Until he does so, he labors under a curse. He writes not of love but of lust, of defeats in which nobody loses anything of value, of victories without hope and, worst of all, without pity or compassion. His griefs grieve on no universal bones, leaving no scars. He writes not of the heart but of the glands.

Until he relearns these things, he will write as though he stood among and watched the end of man. I decline to accept the end of man. It is easy enough to say that man is immortal simply because he will endure: that when the last dingdong of doom has clanged and faded from the last worthless rock hanging tideless in the last red and dying evening, that even then there will still be one more sound: that of his puny inexhaustible voice, still talking.

I refuse to accept this. I believe that man will not merely endure: he will prevail. He is immortal, not because he alone among creatures has an inexhaustible voice, but because he has a soul, a spirit capable of compassion and sacrifice and endurance. The poet's, the writer's, duty is to write about these things. It is his privilege to help man endure by lifting his heart, by reminding him of the courage and honor and hope and pride and compassion and pity and sacrifice which have been the glory of his past. The poet's voice need not merely be the record of man, it can be one of the props, the pillars to help him endure and prevail." Prevod: R. Šoškić.

2 Fokner je često govorio o Don Kihotu kao omiljenom štivu koje je iznova čitao. 
Mirjana Lončar-Vujnović, Radoje Šoškić: Vilijam Fokner $i$ „cela istina”...

\section{1. „VoŠ” I „RUŽA ZA EMILI”: DELIĆ LUDILA U HEROJSTVU?}

Pripovetka „Voš” (“Wash”), objavljena 1934. godine i kasnije revidirana i inkorporirana u Avesalome, Avesalome! (Absalom, Absalom!), ilustruje tipične Foknerove kvalitete, to jest kombinaciju ljudskih vrlina s onim kukavičkim, bizarnim, grotesknim i abnormalnim u čoveku. Voš Vilijams je beznačajni belac koji godinama životari na plantaži Satpenovih. Svom gazdi Satpenu on se divi do granice obožavanja, nalazeći smisao u svom životu kroz Satpenovu slavu. Vošu pričinjava izuzetno zadovoljstvo sama činjenica da mu je dozvoljeno da povremeno pije sa Satpenom, čak iako je „njegov um znao da je to zato što Satpen nije imao druga posla, jer je bio čovek koji nije mogao da podnese ni samoga sebe"” (HART - GoHDES 1958: 899). Međutim, iako je njegov um sve to znao, Voš je tvrdoglavo odbijao da prizna i uvidi snishodljiv odnos svog gazde prema njemu, na šta ukazuju čak i njihov položaj dok sede skupa: Satpen se nalazi u visećoj mreži za ležanje, dok Voš čuči naslonjen na kolac. Voš smatra Satpena svojom apoteozom:

Posle građanskog rata, u kojem je Satpen izgubio gotovo sve, on zavodi Vošovu unuku, Mili, u nastojanju da mu ona rodi sina i tako nastavi lozu. Voš je svestan svega što se zbiva, ali želi da veruje da Satpen postupa časno i da će on „učiniti pravu stvar”. Kada se rodi beba - devojčica, Voš uviđa da Satpenu više od njegovog potomstva vredi potomstvo njegovog pastuva, te tako zaključuju da Satpen nema i nikada nije imao nikakav obzir prema njemu kao čoveku/osobi, a kamoli prema Mili i njenoj kćerki i drugim siromašnim belcima:

Činilo mu se da je prvi put video posle pet godina kako su Jenkiji ili neke druge armije uspevale da ih bičuju: oni plemeniti, ponositi, hrabri; priznali i izabrali najbolje među njima da budu nosioci hrabrosti, časti i ponosa. Da je otišao u rat sa njima, otkrio bi ih možda ranije. No, da ih je ranije otkrio, šta bi uradio sa svojim životom? Kako je mogao da se seća pet dugih godina kakav je bio njegov pređašnji život? (HART - GOHDES 1958: 903)4

3 U originalu: "his mind knew that it was because Sutpen had nothing else to do, being a man who could not bear his own company". Prevod: R. Šoškić.

4 U originalu: "It seemed to him that he now saw for the first time, after five years, how it was that Yankees or any other living armies had managed to whip them: 
Voš istovremeno spoznaje svu nečovečnost „plemenitih, ponositih, hrabrih" aristokrata i optužuje društvenu strukturu Juga da je zatrovana inherentnim zlom:

Bolje da njegova i moja loza nikada nisu ni počeli da žive na ovoj zemlji. Bolje je $i$ da svi oni koji budu preostali od nas budu zbrisani sa lica zemlje nego da još jedan Voš Džouns posmatra kako celi njegov život biva otkinut od njega $i$ zgasne poput suve mahune bačene u vatru. (IBID) $)^{5,6}$

Nejednakost u odnosima između crnaca i belaca, i belaca i belaca, pa čak i idealizacija vladajuće klase koja ugnjetava crnce i siromašne belce jeste ono što Voš oštro osuđuje.

Pošto je tako korigovao sopstvenu percepciju Satpena, Voš ubija Satpena kosom. Nakon što se spustio mrak, kada je Satpenovo telo pronađeno i policijski odred dolazi po Voša, on ubija Mili i bebu, poliva svoju staru daščaru benzinom, zapali je, a zatim istrčava iz nje, u plamenu, u kišu metaka koje u njega ispaljuje policijski odred.

Završetak pripovetke podseća na kraj grčke tragedije. Priča, uistinu, tematizuje brojne stvari, ali jedna od njih jeste poslednji gest Vošov, koji je do te mere skopčan s onim veličanstvenim i zlim u ljudskoj prirodi da se oni ne mogu suštinski odvojiti. Kritikujući tragediju zbog njene tendencije da rafinira emocionalni život čoveka i daje mu izvesnu dozu stila, Oldos Haklsi tvrdi u svom eseju „Tragedija i Cela Istina” da sve dok tragedija uvek predstavlja prečišćenu suštinu ljudske prirode iz koje je podlost/pokvarenost posve eliminisana, komedija uvek kazuje celu istinu, zadržavajući sve ono što tragedija eliminiše. Metod tragičara, prema

the gallant, the proud, the brave; acknowledged and chosen best among them all to carry courage and honor and pride. Maybe if he had gone to the war with them he would have discovered them sooner. But if he had discovered them sooner, what would he have done with his life since? How could he have borne to remember for five years what his life had been before?” Prevod: R. Šoškić.

5 Kurziv autora rada.

6 U originalu: "Better if his kind and mine too had never drawn the breath of life on this earth. Better that all who remain of us be blasted from the face of the earth than that another Wash Jones should see his whole life shredded from him and shrivel away like a dried shuck thrown onto the fire." Prevod: R. Šoškić. 
Mirjana Lončar-Vujnović, Radoje Šoškić: Vilijam Fokner i „,ela istina”...

Haksliju, sastoji se u njegovom „izolovanju jednog elementa iz totaliteta ljudskog iskustva i njegovom korišćenju istog kao jedinstvenog materijala. Tragedija je nešto što je izdvojeno od Cele Istine, prečišćeno od nje, takoreći, poput esencije koja se dobija prečǐsćavanjem cveta. Tragedija je hemijski čista."”

Hakslijeva argumentacija sastoji se u tome da je tragedija „hemijski čista" budući da ona predstavlja, opisuje i usredsređuje se samo na jednu stranu ljudskog duha odnosno prirode odnosno karaktera. Iz ovoga se nesumnjivo može zaključiti da se ljudsko bivstvo nikada ne nalazi u čistom obliku. Komedija, naprotiv, kazuje celu istinu o ljudskim bićima predočavanjem svih strana ljudskog duha/prirode/karaktera. Stoga, Haksli je naziva „hemijski nečistom” formom. U tom smislu shvaćeno, Foknerovo stvaralaštvo uvek je komično, pošto uključuje i ljudske mane, odnosno sve ono što tragedija izostavlja.

„Ruža za Emili” (“A Rose for Emily”) ilustruje Foknerov svet još podrobnije. Ova složena i disperzivna priča govori o ženi - potomku aristokratije u gradu Džefersonu, sedištu Joknapatafa okruga 1928. godine - i o načinu na koji su na nju gledali stanovnici ovog grada tokom više godina. Narator koristi zamenicu „mi”, ${ }^{8}$ i pripoveda u ime svih meštana grada Džefersona. Doznajemo da je Emili Grirson proživela svoju mladost pod kontrolom i budnim okom svog previše dominantnog i zaštitnički nastrojenog oca. Posle njegove smrti, ona se povukla u sebe i provela preostale godine života zatvorena u velikoj kući koju je nasledila. Zbog života u raskoraku sa kodeksima malene zajednice, patnje usled emocionalne krize još od detinjstva, krize neuzvraćene ljubavi u sadašnjosti, Emili biva dovedena do ludila. Međutim, važno je ponoviti činjenicu da je i njena ličnost pogoršala njeno stanje. Ostalim građanima uvek je delovala arogantno i svojeglavo. Na primer, ignorisala je savete sveštenika i nastavila svoj romantični odnos sa Homerom Baronom; takođe, nije poštovala zakone koji su

${ }^{\gamma}$ Hakslijev esej se može proćitati na internetu. Dostupno preko: http://www.vqronline.org/essay/tragedy-and-whole-truth.

$\&$ Ovakav tip naracije koji se može označiti kao horska naracija retko se sreće u književnosti. 
zahtevali da ona plaća porez ili da kaže apotekaru zašto joj je bio potreban otrov. Ukratko, ona je smatrala da je iznad gradske vlasti ili bilo kojeg drugog autoriteta.

U poslednjem paragrafu ove priče čitalac saznaje da je poremećena Emili pre nekoliko godina otrovala svog ljubavnika koji je nameravao da je napusti i da je čuvala njegovo telo u spavaćoj sobi svoje kuće, i to u krevetu gde je umro; u poslednjoj rečenici priče, čitalac otkriva da je ona i dalje spavala u istom krevetu gde je njen pokojni ljubavnik ležao mrtav, čije telo je sada raspadnuto. Kao što opisuje anonimni narator,

A onda smo primetili da na drugom jastuku postoji udubljenje od nečije glave. Neko od nas je podigao nešto s njega, naginjući se napred, s tom mlitavom i nevidljivom prašinom, suvom i oporom u nozdrvama, i videli smo dugi pramen čeličnosive kose. (CASSILL 1978: 486). ${ }^{9}$

Emili je naravno luda, a njena emocionalna utučenost je direktno odgovorna za njeno konačno uništenje, to jest ludilo, ali naslov priče se odnosi na poklon u vidu ruže koji joj je stanovništvo grada uručilo zbog njenog odbijanja da se preda, načini kompromis i prilagodi se i povinuje sve prljavijem i grubljem svetu oko nje; kao što su kritičari primetili, moguće je da postoji delić ludila u herojstvu.

Na kraju, da upotrebimo Hakslijeve reči, Fokner uvek daje čitaocima „celu istinu”, tragično i komično istovremeno su pomešani - kao što je, za čitaoca, smeh, tuga, osećanje užasa i divljenja.

9 U originalu: "Then we noticed that in the second pillow was the indentation of a head. One of us lifted something from it, and leaning forward, that faint and invisible dust, dry and acrid in the nostrils, we saw a strand of iron gray hair." Prevod: R. Šoškić. 
Mirjana Lončar-Vujnović, Radoje Šoškić: Vilijam Fokner $i$ „cela istina”...

\section{DOK LEŽAH NA SAMRTI: ILUSTRACIJA FOKNEROVOG SVETA KOJI JE ISTOVREMENO KOMIČAN, TRAGIČAN, PATETIČAN, OTUŽAN, SMEŠAN I HEROJSKI}

Foknerovo remek delo Dok ležah na samrti (1930) ilustruje iste navedene ideje, ali uz dodatnu tehničku virtuoznost. Zaplet romana se vrti oko siromašne porodice sa sela čiji članovi prevoze telo svoje majke u grad Džeferson ne bi li je sahranili. Na tom putu porodica nema sreće, a niz nesreća dovodi do toga da oni stalno kasne, tako da im je potrebno devet dana da dođu do Džefersona, kada je i telo pokojnika u drvenom sanduku počelo da gadno zaudara i privlači muve.

$\mathrm{S}$ jedne strane, roman je priča o herojskom putovanju, kroz poplave i vatru, da bi se održalo obećanje. Takođe otkrivamo da neki članovi porodice imaju lične motive i razloge iz kojih žele da odu u Džeferson; još jednom da ponovimo, u svakom trenutku bilo čije postupanje se može tumačiti iz više različitih uglova gledanja: kao groteskno, apsurdno, komično, užasno ili plemenito.

Narativna tehnika u ovom romanu je naročito upečatljiva i inovativna. Priča je ispričana u 59 delova od strane 15 likova, od kojih su većina članovi porodice Bandren, ali neke od tih delova pripovedaju i drugi ljudi koji ih susreću na putu za Džeferson. Kao u Orkanskim visovima Emili Bronte, svi naratori se nalaze „unutar priče”, bez sveznajućeg pripovedača koji nam govori šta se zaista dogodilo i kako da sudimo o onome što se dogodilo. Svaki od 59 delova koristi tehniku toka svesti ili unutrašnjeg monologa, što predskazuje normativnu subjektivnost literature u 20. veku (v. LONCAR-VuJNOVIC 2012: 124-147). Pored toga, neki likovi su optrećeni raznim mukama, a njihovi unutrašnji monolozi ilustruju te njihove probleme: Vardaman, najmlađi sin, potpuno je traumatizovan zbog smrti svoje majke; Darl, drugi sin, toliko je intuitivan da može gotovo da čita misli drugih likova, ali je takođe toliko nestabilna ličnost da ga je porodica ostavila u bolnici za umobolne. Ostali likovi (koji nisu članovi ove porodice) svojim različitim perspektivama obogaćuju putovanje porodice, tako da do tre- 
nutka kada je Edi Bandren sahranjena, vidimo čitav niz događaja kroz mnoge dimenzije.

Postoje, osim toga, „podzapleti” unutar same porodice. Neki članovi porodice imaju tajne koje žele da sakriju od drugih - tajne koje Darl može otkriti svojim intuitivnim uvidima, čime bi pomogao da se objasni zašto je porodica spremna da ga ostavi na kraju priče - što komplikuje odnose među članovima porodice. Edi, pokojnici, dodeljen je poduži monolog u kojem nam govori da jedno od njene dece nije dete njenog supruga, već lokalnog propovednika, koga je upoznala u šumi kada je spoznala da njen suprug nije u stanju da je spase od osećanja usamljenosti. Njen monolog, na neki način, jeste ključ za sve što se dešava u knjizi kao i za monologe drugih likova.

Roman takođe ukazuje na određeni trenutak u modernoj američkoj istoriji. Fokner je počeo pisati Dok ležah na samrti dan nakon pada berze 1929. godine. Taj sudbonosni dogadaj označio je kraj Burnih dvadesetih (eng. the Roaring Twenties) i pripovestima o individualizmu i preduzetničkoj agresivnosti (kakve je, recimo, pisao F. S. Ficdžerald), i početak perioda priča o saradnji i zajedničkim naporima (Džon Stajnbek i njegov roman Plodovi gneva). Dok ležah na samrti savršeno obuhvata oba perioda: reč je o porodici koja je na epskom putovanju, o svakom njenom članu koji je vođen ličnim potrebama, ali od kojih svako takođe može podrediti te potrebe većim i značajnijim porodičnim namerama. Edi najzad biva sahranjena. Delo takođe ilustruje Foknerov svet kao istovremeno komičan, tragičan, patetičan, otužan, smešan, groteskan i herojski. To je još jedan u nizu načina na koji Fokner uvek govori surovu „celu istinu”.

\section{DOK LEŽAH NA SAMRTI: TRAGEDIJA GUBITKA SEBE}

Dok ležah na samrti kao remek delo pisano tehnikom toka svesti, koje pripoveda, preko smrti majke, o još većoj tragediji, predstavlja gubitak sebe. Ovo Foknerovo delo istražuje prirodu smrti i umetnosti kroz smrt majke i misli članova njene porodice kao i iskušenja ko- 
Mirjana Lončar-Vujnović, Radoje Šoškić: Vilijam Fokner i „,ela istina”...

jima ovi bivaju podvrgnuti. Ovaj roman o ljudskoj metamorfozi oduševljava čitaoca svojim razumevanjem prirodnih sila izvan ljudskog sveta i kontrole. Možda je najsnažnija figura u romanu sam kovčeg: Šta sadrži taj kovčeg?, neprestano pita ova knjiga o elementarnim silama, Šta znači sadržati nešto? Ključna tema u knjizi je susret: susret sa drugima, sa prirodnim svetom. U klimaktičnom momentu, porodična zaprežna kola (na kojima je telo majke u sanduku) ulaze u vodu, i foknerovsko „krštenje” se tad dešava: uranjanje u elemente. Ali to je krštenje u suprotnom smeru, obrnuto krštenje, zato što se „ja" dezintegriše kada biva podvrgnuto takvom pritisku. Naslov knjige predstavlja veliko (savremeno) pitanje: Može li ,ja” umreti? Da li je ,ja” fikcija?

Naslov Dok ležah na samrti govori čitaocu sve što je potrebno da zna o romanu u smislu zaključaka do kojih Fokner dolazi o modernom razmišljanju i savremenom životu: smrt pojma sopstvenosti. Buka i bes je bio Foknerov prvi narativ toka svesti, ali se čini da je u romanu Dok ležah na samrti pomenutu tehniku pisac dodatno usavršio, uzimajući u obzir činjenicu da je ovo delo možda i „najfilozofskiji” tekst koji je ikada napisao. Roman ima naizgled jednostavnu temu - odnošenje kovčega sa mrtvom Edi Bandren sa porodične farme do Džefersona radi sahrane. Ova misija generiše složen niz reakcija članova porodice, koje se kreću od različitih mišljenja članova porodice do osoba koji nisu članovi porodične zajednice. Fokner reprizira dilemu Sofoklove Antigone: šta činiti sa telom mrtvaca? Teško da je ovde u pitanju književni motiv; postupanje prema telima mrtvih ključni je element svih religioznih kultura. Međutim, dok moderna literatura tematizuje ljudsku psihu - a Fokner je ovde nezaobilazan - ovaj roman takode nam daje nezaboravan uvid u same elemente, prirodu, koji deluju poput pozornice na kojoj likovi igraju svoje životne uloge. Čitalac se na taj način susreće sa neverovatnim spektrom reakcija na smrt Edi Bandren. Ans, naizgled bespomoćan i nespretan muž, prema kom svi u romanu osećaju prezir, pokazuje zapanjujuću urođenu mudrost; on takođe ima svoje razloge odlaska u Džeferson. On primećuje da su horizontalne stvari, poput puteva i zaprežnih kola, namenjene kretanju, 
a da je Bog načinio ljude i drveće uspravnim kako bi ovi ostali tu gde jesu. Kao što ćemo videti u ovom tekstu, stabilnost je fikcija; ništa ne može ostati netaknuto odnosno stabilno. Džuel, omiljeni sin (koji je, inače, kopile), predstavljen je kao ostrašćeni „bukvalista” čija su osećanja prema majci u velikoj meri neizreciva i neizrečena. On simbolizuje fizičku snagu u porodici. Keš, stolar, je pragmatičar u knjizi, čovek koji se izražava jezikom zanatlije. On je izradio kovčeg, a njegova majka s pravom vidi to kao izraz ljubavi.

Darl, filozof, najautoritativnija je figura romana: sposoban za izlete u domen metafizike, blagosloven i proklet sa nekom vrstom rendgenskog uvida u psihologiju drugih, a ipak neuravnotežen. U jednoj ranoj sceni romana, Darl se seća da je ustajao noću da bi popio malo vode. Kada stavlja crpku u kantu, on „razbuđuje zvezde.” Na tragu Marsela Prusta, Sekspira i drugih, Darl kaže:

U nepoznatoj sobi moraš se potpuno isprazniti kako bi zaspao. A pre nego se isprazniš za spavanje, šta si. A kad si ispražnjen za spavanje, nisi. I kad si ispunjen snom, nikada nisi bio. Ja ne znam šta sam. Ne znam jesam li ili nisam. (FAULKNER 1985: 40) ${ }^{10}$

Drugim rečima, ako je čovek samo telo koje spava, onda on nema svest, čovek onda nije. Isti pasus se završava rečima: „Koliko puta ležah po kiši na tuđem krovu i mišljah o domu?” (IBID). Čitalac shvata da je ovaj lik u suštini beskućnik, kako je sam um/racio „prognao” Darla iz bilo kakvog osećanja utemeljenosti. Djui Del je neudata, trudna kćerka čija je reakcija na smrt njene majke neodvojiva od njenih osećanja vezanih za trudnoću. Foknerova priča o njenim osećanjima da nosi život u sebi kompatibilna je sa njenim ne manje moćnim osećanjem urušavanja identiteta/sebe. Vardaman, najmlađe dete, takođe je najumobolnija figura romana, a njegovu traumu nezaboravno prenose foknerovska asocijativna logika i zapanjujuće metafore. U trenutku kada njegova majka umire, Vardaman hvata ogromnu ribu. U njegovom umu, ova

10 U originalu: "In a strange room you must empty yourself for sleep. And before you are emptied for sleep, what are you. And when you are emptied for sleep, you are not. And when you are filled with sleep, you never were. I don't know what I am. I don't know if I am or not." Prevod autora rada. 
dve stvari bivaju pobrkane: njegova majka ne može biti mrtva jer je bila još živa kada se riba praćakala. Kada je zatvoren sanduk sa telom Edi, Vardaman buši rupe u sanduku, da se ona ne bi ugušila.

Reakcije porodice na smrt Edi dramatično su upoređene sa ne manje raznolikim reakcijama suseda i građana na njenu smrt i ovaj putujući kovčeg koji počinje zaudarati na vrelini Misisipija. Pibodi, lekar u knjizi, nudi neke od najspekulativnih ideja o fenomenu smrti:

Sećam se kako sam u mladosti verovao da je smrt fizička pojava; a sada znam da je to puka funkcija duha - i to duha onih koji su pretrpeli gubitak. Nihilisti kažu da je to kraj; fundamentalisti kažu da je to početak; a u stvarnosti nije više od selidbe stanara ili porodica iz stana ili grada. ${ }^{11}$ (FAuLKNER 1985: 21).

Osnovna slika romana sadržana je u ideji o smrti kao stanara koji se iseljava iz doma. Poput doma, kovčeg je spremnik, ali šta je to što on sadrži? Telo? Dušu? Identitet - Ja? Kasnije u romanu, čitalac biva primoran da se zapita da li čak i jezik sadrži značenje. Tal, komšija, služi kao nekakav barometar, zdravorazumska figura u romanu, koja na trenutke pokazuje vizionarske uvide. On nam saopštava da tuga i bolest mogu da obuzmu i napadnu čoveka bilo gde i bilo kada, poput munje.

${ }^{11}$ U originalu: "I can remember how when I was young I believed death to be a phenomenon of the body; now I know it to be merely a function of the mind and that of the minds of the ones who suffer the bereavement. The nihilists say it is the end; the fundamentalists, the beginning; when in reality it is no more than a single tenant or family moving out of a tenement or a town." Prevod: R. Šoškić. 


\section{IZVORI I CITIRANA LITERATURA}

Faulkner, William. The Portable Faulkner. Edited, with an Introduction and

Notes by Malcolm Cowley. New York: Viking Press, 1946.

Faulkner, William. "A Rose for Emily," reprinted in The Norton Anthology of Short Fiction, R. V. Cassill (ed.), New York: Norton, 1978, 479-486.

Faulkner, William. As I Lay Dying. New York: Vintage International-Vintage Books, 1985.

Frenz, Horst (ed.), Nobel Lectures, Literature 1901-196\%. Amsterdam: Elsevier Publishing Company, 1969.

HART, D. James and Clarence GoHDEs (eds.). "Wash". American Literature. New York: Holt, Rinehart, and Winston, 1955.

HuxLEy, Aldous. "Tragedy and the Whole Truth." 21 March 1931, The Spectator Archive, http://archive.spectator.co.uk/article/21st-march-1931/9/ tragedy-and-the-whole-truth. [10/04/2018]

Loncar-Vujnovic, Mirjana. Stream of Consciousness Technique: The Most Impressive Innovation in Modern Literature. Kosovska Mitrovica: Filozofski fakultet, 2012.

Rossky, William. "As I Lay Dying: The Insane World." Texas Studies in Literature and Language, Vol. 4, No. 1, University of Texas Press, Spring 1962, 87-95.

VuKČEvić, Radojka. Fokner i mit: mitološki motivi u Foknerovom pripovijedanju. Podgorica: Univerzitet Crne Gore, 1997. 
Mirjana Lončar-Vujnović, Radoje Šoškić: Vilijam Fokner i „,cela istina”...

Mirjana Lončar-Vujnović

Radoje Šoškić

\section{WILLIAM FAULKNER AND "THE WHOLE TRUTH" ABOUT HUMAN BEINGS IN "WASH," "A ROSE FOR EMILY," AND AS I LAY DYING}

\section{Summary}

The Nobel Prize William Faulkner was awarded in 1950 rescued his works from the realm of the sensational and the regional. His acceptance speech reminded readers that his stories were about traditional values, even if they occurred in unusual circumstances and contexts. We use two short stories, "Wash" and "A Rose for Emily," to illustrate Faulkner's characteristic combination of human greatness with the bizarre, the grotesque, and even the insane. We account for this unusual combination in the conceptual framework provided by Aldous Huxley's essay, "The Whole Truth." Then we introduce Faulkner's novel, As I Lay Dying, in that framework, showing that like all of his works, the comic, tragic, pathetic, sad, funny, grotesque, and the heroic are always so close to each other that they cannot be separated - which is, as Huxley would say, the "whole truth" about human beings.

Key words: Faulkner, the whole truth, tragedy, comedy, human condition, "Wash", ”A Rose for Emily", As I Lay Dying.

Univerzitet u Prištini sa privremenim sedištem u Kosovskoj Mitrovici

Filozofski fakultet

loncar.mirjana@gmail.com

soskicradoje@gmail.com 